presented text. A good book and good value for money.

Pat Morris, Lecturer in Zoology, Royal Holloway College, University of London

\section{Threatened Swallowtail Butterflies of the \\ World (The IUCN Red Data Book) \\ N. Mark Collins and Michael G. Morris \\ IUCN, Gland, Switzerland, and Cambridge, UK, HB $£ 18.00$}

This 400-page volume includes five major sections: the biology of papilionids and their basic conservation requirements, distribution and status, critical faunas analysis, trade, and a review of threatened species; two appendices: swallowtails in threatened categories, and species requiring further research; an index; and eight colour plates illustrating 40 of the threatened taxa.

The informative first section is followed by a 100 page encyclopaedia, with entries for all 573 recognized species. Such a truly systematic approach lays the foundation for the unique qualities of this book. To quote the authors, this is the first worldwide assessment of the conservation needs of any invertebrate group, and the first Red Data Book to be based on a published consideration of every species in the taxon under review'. Bold claims-fully vindicated by the text. Their approach is vital for two major reasons: first, it makes such a work invaluable in its own rightCollins and Morris is not merely a review, it is a primary reference source. Secondly, the comprehensive approach permits quantification, such as the critical faunas analysis presented in Part 3, which indicates a 'top 5' list of Indonesia, Philippines, China, Brazil and Madagascar. Between them, these countries possess more than half the world's swallowtail butterfly species-including 110 not found anywhere else. Clearly, any swallowtail conservation strategy that fails to involve these five nations cannot be effective. One wonders what sort of list would emerge from similar treatment of a variety of plant as well as animal groups - 'critical FF-analysis'.

Such considerations pose a further question: have those organizations responsible for global conservation programmes already done this work-or is species conservation essentially ad hoc? Of course, complete objectivity is never possible, and reality is often overwhelmingly Book reviews complex. Nonetheless, I believe that it is essential to develop methods that allow as much objectivity as possible, and reduce complexities to manageable proportions. What I like so much about this latest Red Data Book is that it offers a way forward from the apparently random approach to so much conservation planning.

If it should be contended that time is too short to make such global assessments, and the data are too hard to find, then one need only point to this remarkable book, completed in only two years. In fact, there is no lack of data-it is just a matter of getting on with it, extracting, collating, organizing, analysing. Now we even have cheap computers to help us. Is there, then, some lack of will-are we frightened to take a global view, to make choices, make rational decisions, for fear of having to put our own pet projects into perspective, or even into limbo?

I consider this book to be an outstanding achievement. On first picking it up, I was struck by a moment's egotistical sadness-why hadn't I written this thing myself! Threatened Swallowtail Butterflies of the World represents a watershed in our approach to species conservation strategy.

R. I. Vane-Wright, Department of Entomology, British Museum (Natural History)

\section{The Wilderness Guardian-A Practical Guide to Fieldwork Related to Wildlife Conservation Timothy Corfield}

Published by the David Sheldrick Wildlife Appeal, PO Box 48177, Nairobi, Kenya, and available in UK from the Eden Wildlife Trust, 10 Oriel Hill, Camberley, Surrey GU15 2JW, UK, $£ 15$ plus $£ 1.50$ for postage and packing

This is one book that I hope never to see on a conservationist's bookshelf, but rather in his pocket or on the dashboard of his landrover, for this is an eminently practical volume.

Dedicated to the memory of David Sheldrick, first warden of Tsavo East National Park, Kenya, it is an encyclopaedic compilation of the diverse skills and knowledge a game warden is expected to possess. The information on wildlife is specific to Africa, but the book would be of value to wardens and park rangers in any country. The natural history section is a curious selection-26 pages on insects, one-and-a-half pages on snakes and 